\title{
CONCENTRATE DISTRIBUTION TO SHEEP USING AUTOMATIC FEEDING STATION
}

\author{
Līga Šenfelde, Daina Kairiša \\ Latvia University of Agriculture \\ shenfeldel@gmail.com
}

\begin{abstract}
The research was conducted with the aim of studying the possibility of using automatic feeding stations for individual sheep (Ovis aries) feeding. The research was organized in 3 periods, in which 10-13 months old sheep - female only (1st research period), 6-10 months old sheep - female only ( 2 nd research period) and 8-12 months old sheep - female only (3rd research period) were used. Part of the sheep did not visit the feeding station at all. Sequentially, over the research periods the percentage was $13 \%, 37 \%$ and $49 \%$. Upon setting the concentrate daily ration 400 g per sheep, on the average the number of visits to the particular feeding station was 6.1 and 4.7 (sequentially in the 1 st and 2 nd research period). Upon increasing the concentrate ration amount up to $700 \mathrm{~g}$ per day, the average number of feeding station visits was 6.9 (in the $3 \mathrm{rd}$ research period). The number of visits to the automatic feeding station was varied $(\mathrm{V}>10 \%)$. Over the research period live weight of the sheep increased significantly $(\mathrm{p} \leq 0.05)$ for the subgroups of animals which made visits to the feeding station regularly during the entire research period. In all research periods, the average daily concentrate intake $\left(373.5 \mathrm{~g}\right.$ in the $1^{\text {st }}$ research period, $333.1 \mathrm{~g}$ in the $2 \mathrm{nd}$ research period and $581.2 \mathrm{~g}$ in the 3 rd research period) was $93 \%, 83 \%$ and $83 \%$ respectively, of the maximum established feeding standard.
\end{abstract}

Key words: feeding station, pelleted concentrate, intake.

\section{Introduction}

Since 1950 balanced nutrition of ruminants held in sheds has been in the focus of increased attention. For this purpose a special research was launched (Ungar, 1996).

Determination of the quantity of forage consumed by an animal and that, which is necessary, is important for animal cost and productivity level balancing. It has been proven by studies that poor nutrition of ewes during pregnancy lowers lamb live weight at birth (Robinson, McEvoy, \& Sinclair, 1999), increases lamb mortality rate (Jordan \& Mayer, 1989; Kleeman et al., 1993; Hinch et al., 1996) and reduces the amount of colostrum (Hall, Holst, \& Shutt, 1992; O’Doherty \& Crosby, 1996). Insufficiency of nutrients negatively affects uddermass and development, causing delay in the start of lactation (Mellor et al., 1987) and reduces the ewe lactescence (Jordan \& Mayer, 1989; O'Doherty \& Crosby, 1996). At the same time, it is noted that excessive provision of nutrients also has a negative impact on the productivity of sheep (Ocak, Cam, \& Kuran, 2005). When concentrate distribution is organized by scattering in trough, it is possible for stronger animals to push away the rest to consume much more concentrate than the desired diet. As a result, of ruminant feed fermentation volatile fatty acids and lactic acid are produced in the rumen. If an animal is unable to absorb the entire amount of volatile fatty acids and lactic acid produced through fermentation, they accumulate in the rumen and lower pH (Plaizier et al., 2009). Regular (daily) extended period of decreased $\mathrm{pH}$ level (below normal - 6.5) in the rumen has adverse effects on feed intake, nutrient digestion and metabolite formation, as well as causes inflammation, laminitis, diarrhea and reduction in milk fat (Stone, 2004; Krause \& Oetzel, 2006; Enemark, 2008). It has been proven that when highly productive cows are fed large amounts of concentrated feed, there is a tendency for development of acidosis (Bath, 1982) that draws attention to possible disease occurrence in other ruminants as well (Braun, Rihs, \& Schefer, 1992).

Over time multiple methods have been used used to determine the amount of consumed feed. It is a very time-consuming and expensive process, which can be greatly facilitated by making use of computerized data recording software (Demment \& Greenwood, 1987; Unwin \& Martin, 1987). Usage of automatic feed distribution stations in sheep rearing is quite innovative. In Weihenstephan Technical High School Research Farm such an automatic station for feed distribution, which allows feeding concentrate in form of breadstuff or pellets, or finely chopped hay, was used in a research in 1999 (Wendl et al., 1999). Using automatic feeding station to feed concentrates to sheep, it is possible to prevent nutrient shortage or saturation effects. It should be noted that with the automatic feeding station used in this research it is possible to ration concentrate only in the form of pellets.

The aim of this research was to study the possibility of using automatic concentrate feeding stations in sheep individual feeding. To achieve the research goal the following tasks were set: 1) to analyse frequency of visits to automatic feeding station; 2) to analyse changes in sheep live weight; 3 ) to analyse the amount of the daily concentrate intake.

\section{Materials and Methods}

The research on usage of automatic concentrate feeding stations for sheep feeding was carried out on the farm 'Mežoki' located in Latvia (57.016996, 21.632202). The study was carried out in production conditions. In total the research was carried out 
over 3 periods, namely: from 21 February 2015 till 7 May 2015 (1st research period), from 1 November 2015 till 12 December 2015 (2nd research period) and from 13 December 2015 till 16 January 2016 ( 3 rd research period).

In all research periods sheep (only female) for breeding were used. All sheep used in the 1st research period were born in the farm 'Mežoki' flock; at the beginning of the 1st research period there were 48 sheep born in the period from December 2013 till March 2014 (including). In the 1st research period the following sheep breeds were used: XX crossbreed $(\mathrm{n}=10), 50 \%$ Latvian dark-head $\times 50 \%$ Texel $(\mathrm{n}=24)$, $25 \%$ Latvian dark-head $\times 75 \%$ Texel $(n=14)$. The sheep of this group had not received feed concentrate before. In the 2nd research period 136 sheep were used, born in the period from December 2014 till May 2015 (including), except for two sheep, which were born in March 2014. Both sheep born in March 2014 had been used in the 1 st research period as well. The sheep group of this research period consisted of 91 sheep born in the flock on the farm 'Mežoki' and 45 Texel purebred sheep, purchased in Germany in July 2015. In the 2 nd research period the following sheep breeds were used: XX crossbreed $(\mathrm{n}=4), 50 \%$ Latvian dark-head $\times 50 \%$ Texel $(\mathrm{n}=52), 25 \%$ Latvian darkhead $\times 75 \%$ Texel $(n=31)$ and Texel $(n=49)$. Before the 2 nd research period all the sheep of this group had received concentrate in unlimited amounts.
In the 3rd research period the same sheep were studied as in the 2 nd research period, except for one (25\% Latvian dark-head $\times 75 \%$ Texel), which lambed on 13 December 2015 and was taken out of the group. Thus in the $3 \mathrm{rd}$ research period the group consisted of 135 sheep (Table 1 ).

In the 1st research period six sheep did not visit the automatic concentrate feeding station, while during the 2 nd and the 3 rd research periods a total of 48 sheep did not visit the feeding station at all. Regrouping of the animals was observed in the 2 nd and the 3 rd research periods. The data obtained for analysis were grouped depending on the number of days an animal visited the feeding station: data on the sheep which did not visit the feeding station (Group ' $N$ '), on the sheep which visited the feeding station daily during all the period (Group 'P'), and on the sheep which visited the feeding station part of the time period (Group 'D'). The figure following the letter in the name of the group denotes the research period. Data of Group D were subdivided into two other subgroups: data on the sheep which visited the automatic concentrate feeding station less than half of the number of days in the relevant period (group ' 1 ') and data on the sheep which visited the feeding station more than half of the number of days in the relevant period (group '2') (Table 1).

In every research period each sheep group was kept apart in a separate pen. All the sheep of one group

Table 1

\section{Sheep distribution according to the number of days they visited the automatic feeding station}

\begin{tabular}{|c|c|c|c|c|c|c|}
\hline Subgroup & $\begin{array}{l}\text { Average age at the } \\
\text { beginning of research } \\
\text { period, months }\end{array}$ & \multicolumn{2}{|c|}{ Number of sheep } & \multicolumn{2}{|c|}{$\begin{array}{l}\text { Specific weight as } \\
\text { compared with the } \\
\text { total group, } \%\end{array}$} & $\begin{array}{l}\text { Automatic feeding } \\
\text { station visiting, days }\end{array}$ \\
\hline 1st period total, & 11 & \multicolumn{2}{|c|}{48} & \multicolumn{2}{|c|}{100} & - \\
\hline $\mathrm{P} 1$ & 11 & 26 & \multirow{3}{*}{42} & 54 & \multirow{3}{*}{87} & 76 \\
\hline D11 & 11 & 2 & & 4 & & $1-37$ \\
\hline D12 & 11 & 14 & & 29 & & $38-75$ \\
\hline N1 & 11 & 6 & 6 & 13 & 13 & 0 \\
\hline 2nd period total & 8 & \multicolumn{2}{|c|}{136} & \multicolumn{2}{|c|}{100} & - \\
\hline $\mathrm{P} 2$ & 8 & 17 & \multirow{3}{*}{86} & 13 & \multirow{3}{*}{63} & 42 \\
\hline D21 & 8 & 36 & & 26 & & $1-20$ \\
\hline D22 & 9 & 33 & & 24 & & $21-41$ \\
\hline $\mathrm{N} 2$ & 8 & 50 & 50 & 37 & 37 & 0 \\
\hline 3rd period total & 10 & \multicolumn{2}{|c|}{135} & \multicolumn{2}{|c|}{100} & - \\
\hline $\mathrm{P} 3$ & 10 & 54 & \multirow{3}{*}{69} & 40 & \multirow{3}{*}{51} & 35 \\
\hline D31 & 10 & 6 & & 4 & & $1-17$ \\
\hline D32 & 11 & 9 & & 7 & & $18-34$ \\
\hline N3 & 10 & 66 & 66 & 49 & 49 & 0 \\
\hline
\end{tabular}

P1, P2, P3 - group of sheep which visited the feeding station daily during all the period, D11, D21, D31 - subgroup of sheep which visited the automatic concentrate feeding station less than half of the number of days in the relevant period, D12, D22, D32 - subgroup of sheep which visited the feeding station more than half of the number of days in the relevant period. 
were provided continuous access to one automatic concentrate feeding station. The sheep were given free access to hay and water as well. Every third day access to haylage was provided.

In all research periods at the automatic feeding station the sheep were offered concentrate of the same content: $43 \%$ of cereals (barley (Hordeum vulgare L.)), 24\% plant-based protein sources (wheat (Triticum) bran, feed beans (Vicia faba), sunflower (Helianthus annuus) coarse meal, soybean (Glycine max) coarse meal) $20 \%$ alfalfa (Medicago sativa) pellets and $13 \%$ the remaining ingredients (sugar beet (Beta vulgaris subsp. vulgaris) coarse meal, molasses - liquid, $\mathrm{NaCl}$ ). Concentrate content: $83 \%$ of dry matter (DM), protein $19 \%$ in DM, crude fibre $25 \%$ in DM, metabolizable energy (ME) 11.87 $\mathrm{MJ} \mathrm{kg}{ }^{-1}$ of DM, net energy for lactation (NEL) 3.75 $\mathrm{MJ} \mathrm{kg}^{-1}$ of DM, neutral detergent fiber (NDF) $23.51 \%$ in DM, acid detergent fiber (ADF) $8.9 \%$ in DM, $\mathrm{P} 0.49 \%$ in DM, Ca $1.27 \%$ in DM. Under the study the maximum daily concentrate feed rations for one animal according to the sheep groups were determined as follows: in the $1 \mathrm{st}$ research period $-400 \mathrm{~g}$, in the 2 nd research period $-400 \mathrm{~g}$, in the $3 \mathrm{rd}$ research period $-700 \mathrm{~g}$.

Before and after each research period the sheep live weight monitoring was organized with a New Zealand company's Tru-Test automatic weigh scales. Weighing accuracy is $\pm 0.1 \mathrm{~kg}$ for animals with live weight of up to $50 \mathrm{~kg}$ and $\pm 0.2 \mathrm{~kg}$ for animals with live weight of 50-100 kg. Live weight control dates: 7 February 2015 and 24 May 2015 (in the 1 st research period), 18 October 2015 and 12 December 2015 (in the 2nd research period), 12 December 2015 and 16 January 2016 (in the 3rd research period).

After selection of sheep for the 1st and 2nd research periods and checking of live weight, a two week (14 days) adapting period was provided so that the sheep could get used to the automatic feeding station. After the adapting period, data collection in the automatic feeding station was started.

A BioControl Norway JSC compound concentrate feeding station for feeding of individual sheep was used in the study. The external measurements of the feeding station are $2 \times 8 \times 1 \mathrm{~m}$, its mode of operation - continuous. Form of the concentrate feed - pellets. One standard dose dispensed in the feeding station - $25 \mathrm{~g}$, maximum limit of intake at one visit to the feeding station $-100 \mathrm{~g}$. Using the concentrate feeding station the following data were recorded: electronic ID number of the animal visiting the feeding station, date and time of the visit to the feeding station for each sheep, the amount of concentrate dispensed per visit, the amount of concentrate dispensed per day for each sheep after each visit, total concentrate amount for each sheep per day.

The concentrate intake quantity - $0 \mathrm{~g}$ caused as the result of faulty operation of the feeding station because of failure of the electrical power supply. It is possible, if the magnetic plate in the feeding station reads the sheep number, but dispenses no concentrate due to error. Recording of $0 \mathrm{~g}$ dispensed concentrate quantity has been registered only once during the entire period of research. In the 2 nd research period sheep of subgroup P2 had concentrate intake above the determined ration, caused by the power supply failure on 18 November 2015, thus making no significant changes in the registration of concentrate quantity and data analysis, and data represented in the results.

The data were analysed with mathematical processing methods, using free software ' $\mathrm{R}$ Statistics'. The number of visits, quantity of compound concentrate fed, sheep live weight mean values, standard error and coefficient of variation were calculated, as well as the parameters obtained were compared between groups, determining significance of their differences and designating with the lowercase and capital alphabetical characters; a, b, c, A, B $\mathrm{p} \leq 0.05$, or $* * \mathrm{p} \leq 0.01 ; * * * \mathrm{p} \leq 0.001 ; \mathrm{n}$. s. difference is not significant $(\mathrm{p}>0.05)$.

\section{Results and Discussion}

The results of feeding station visits obtained (Table 2) show that in the 1st and the 2nd periods the number of visits of $\mathrm{P} 1$ and $\mathrm{P} 2$ group sheep was the largest (6.2 and 5.2 respectively). The mean number of daily visits was significantly different between the subgroups of the 2 nd research period. The number of visits registered ranged from one to 14 . The maximum (14) visits per day made sheep of subgroups D12 and D22. Mode and median of the number of visits in subgroups of the 1st and 2nd research period are similar. These indicators are similar with the mean number of daily visits too, except subgroup D21.

There was no significant difference among mean values of the number of visits made by sheep subgroups in the 1st research period. In the 2nd research period there existed significant differences $(p \leq 0.05)$ between mean values of the number of visits to the feeding station in all subgroups.

In the 3 rd research period sheep of subgroup P3 had the highest mean number of visits to the concentrate feeding station per day ( 7 visits); the mean number of visits to the automatic feeding station per day differs significantly between all subgroups. In the 3rd research period the mean number of visits to the concentrate feeding station per day for all subgroups was higher (6.9 visits) than in the 1st and 2 nd research periods (6.1 and 4.7 visits, respectively) as well, which can be explained by the fact that in the 3rd period the 
Daily number of visits to the automatic feeding station

\begin{tabular}{|l|c|c|c|c|c|c|}
\hline Group & $\overline{\mathrm{x}} \pm \mathrm{S}_{\overline{\mathrm{x}}}$ & Min & Max & Median & Mode & V\% \\
\hline 1st period total & $6.1 \pm 0.03^{\mathrm{A}}$ & 1 & 14 & 6 & 6 & 28 \\
\hline P1 & $6.2 \pm 0.04^{\mathrm{a}}$ & 1 & 13 & 6 & 6 & 27 \\
\hline D11 & $6.1 \pm 0.23^{\mathrm{a}}$ & 1 & 9 & 6 & 6 & 23 \\
\hline D12 & $6.0 \pm 0.06^{\mathrm{a}}$ & 1 & 14 & 6 & 6 & 32 \\
\hline 2nd period total & $4.7 \pm 0.04^{\mathrm{B}}$ & 1 & 14 & 5 & 5 & 37 \\
\hline P2 & $5.2 \pm 0.06^{\mathrm{a}}$ & 1 & 10 & 5 & 5 & 29 \\
\hline D21 & $2.3 \pm 0.16^{\mathrm{b}}$ & 1 & 7 & 1 & 1 & 79 \\
\hline D22 & $4.7 \pm 0.05^{\mathrm{c}}$ & 1 & 14 & 5 & 5 & 35 \\
\hline 3rd period total & $6.9 \pm 0.05^{\mathrm{a}}$ & 1 & 14 & 7 & 8 & 31 \\
\hline P3 & $7.0 \pm 0.04^{\mathrm{a}}$ & 1 & 14 & 7 & 8 & 28 \\
\hline D31 & $1.9 \pm 0.24^{\mathrm{b}}$ & 1 & 6 & 1 & 1 & 74 \\
\hline D32 & $6.2 \pm 0.20^{\mathrm{c}}$ & 1 & 12 & 7 & 8 & 46 \\
\hline
\end{tabular}

$\mathrm{a}, \mathrm{b}, \mathrm{c}$ - there are significant differences between subgroups, $\mathrm{p} \leq 0.05$, the differences between subgroups are determined separately within the limits of each research period. ${ }^{\mathrm{A}, \mathrm{B}}$ - there are significant differences between results of research periods in total, $\mathrm{p} \leq 0.05$. P1, P2, P3 - group of sheep which visited the feeding station daily during all the period, D11, D21, D31 - subgroup of sheep which visited the automatic concentrate feeding station less than half of the number of days in the relevant period, D12, D22, D32 - subgroup of sheep which visited the feeding station more than half of the number of days in the relevant period.

daily concentrate ration was increased (from $400 \mathrm{~g}$ in the 1 st and 2 nd research periods to $700 \mathrm{~g}$ in the $3 \mathrm{rd}$ research period).

In all research periods the coefficient of variation for all subgroups was above $10 \%$, which coincides with the results of Wedl et al. (1999) research.
Comparing the mean values of the daily concentrate intake (Table 3), it can be seen that in the 1 st research period there were significant differences $(p<0.001)$ between subgroups P1 and D12. In the 2 nd research period there were significant differences $(p \leq 0.05)$ between daily concentrate

Table 3

\section{Daily concentrate intake quantity for sheep, $g$}

\begin{tabular}{|l|c|c|c|c|}
\hline Group & $\overline{\mathrm{x}} \pm \mathrm{S}_{\overline{\mathrm{x}}}$ & $\mathrm{V} \%$ & Min & Max \\
\hline 1st period total & $373.5 \pm 1.17^{\mathrm{A}}$ & 18 & 0 & 775 \\
\hline P1 & $378.4 \pm 1.32^{\mathrm{a}}$ & 16 & 0 & 775 \\
\hline D11 & $391.3 \pm 5.41^{\mathrm{ab}}$ & 9 & 25 & 475 \\
\hline D12 & $362.7 \pm 2.33^{\mathrm{b}}$ & 21 & 25 & 525 \\
\hline 2nd period total & $333.1 \pm 2.42^{\mathrm{B}}$ & 32 & 25 & 425 \\
\hline P2 & $356.6 \pm 3.20^{\mathrm{a}}$ & 24 & 50 & 425 \\
\hline D21 & $168.5 \pm 12.12^{\mathrm{b}}$ & 80 & 25 & 400 \\
\hline D22 & $336.4 \pm 2.99^{\mathrm{c}}$ & 30 & 25 & 400 \\
\hline 3rd period total & $581.2 \pm 3.61$ & 29 & 25 & 700 \\
\hline P3 & $597.4 \pm 3.38^{\mathrm{a}}$ & 25 & 25 & 700 \\
\hline D31 & $133.3 \pm 20.83^{\mathrm{b}}$ & 90 & 25 & 575 \\
\hline D32 & $500.6 \pm 15.34^{\mathrm{c}}$ & 44 & 25 & 700 \\
\hline
\end{tabular}

$\mathrm{a}, \mathrm{b}, \mathrm{c}$ - there are significant differences between subgroups, $\mathrm{p}<0.05$, the differences between subgroups are determined separately within the limits of each research period. ${ }^{\mathrm{A}, \mathrm{B}}$ - there are significant differences between results of research periods in total, $\mathrm{p} \leq 0.05$. P1, P2, P3 - group of sheep which visited the feeding station daily during all the period, D11, D21, D31 - subgroup of sheep which visited the automatic concentrate feeding station less than half of the number of days in the relevant period, D12, D22, D32 - subgroup of sheep which visited the feeding station more than half of the number of days in the relevant period. 
intake in all subgroups. In both periods the average daily concentrate intake was in the range from $168.5 \mathrm{~g}$ (subgroup D21) to $391.3 \mathrm{~g}$ (subgroup D11). In the 1st period subgroup D11 sheep had the biggest amount of daily concentrate intake (391.3 g) and in the 2nd research period - the sheep of subgroup P2 (356.6 g). The lowest average quantity of concentrate intake coincides with the lowest average number of visits to the feeding station for subgroups D12 and D21 (Table 2 and Table 3).

In the $1 \mathrm{st}$ and the 2 nd research periods the variation coefficient of the concentrate intake quantity for all subgroups (except subgroup D11) is above $10 \%$. Subgroup D21 has the highest coefficient of variation of the concentrate intake quantity $(80 \%)$ and it also has the highest coefficient of variation $(79 \%$, Table 2) of the number of visits to the concentrate feeding station. The results for all subgroups in relation to the number of visits to the feeding station as well as to the quantity of feed intake point to the fact that the registered data are varied. It confirms the observation of Wendl et al. (1999) in the research done in 1999 on too great a scatter of the data depending on the type of food and the sheep individual needs.

After summarizing the mean values of feed intake in the 3rd research period, it is evident that there exist significant differences $(\mathrm{p} \leq 0.05)$ between all subgroups (Table 3 ). In the $3 \mathrm{rd}$ research period the average quantity of daily concentrate intake was $581.2 \mathrm{~g}$. Sheep of subgroup P3 had the biggest daily concentrate intake quantity $(597.4 \mathrm{~g})$. The coefficient of variation of concentrate intake for the sheep groups of the $3 \mathrm{rd}$ research period is in the range from $25 \%$ (for subgroup P3) to 90\% (for subgroup D31).

Figure 1 shows a strong positive relationship between the average daily concentrate intake and the average number of visits to the feeding station, as it was also indicated by the resulting correlation coefficient $(\mathrm{r}=0.69, \mathrm{p}<0.001)$. Coefficient of determination was 0.522 and y value indicates if the number of daily visits to the feeding station increase is 1 , it results in $52.74 \mathrm{~g}$ increase of daily concentrate intake.

Sheep average live weight before entire research period were compared. There were no significant differences $(p>0.05)$ between sheep average live weight within groups. Also sheep average live weight after entire research period were compared, there were no significant differences $(p>0.05)$ within groups and subgroups. Absence of significant differences between sheep subgroup average live weight after each research period can be explained by the fact that for the sheep subgroups, the average live weight of which was higher at the beginning, the average live weight gain was lower (N1, D21, D1), as compared with the sheep subgroups, the average live weight of which was lower at the beginning of the relevant research period $(\mathrm{P} 1, \mathrm{P} 2, \mathrm{D} 31, \mathrm{P})$. The positive influence of concentrate on live weight gain has been proved also for animals during the grazing season (Bosing et al., 2014).

Ater comparing the mean values (Table 4), the following sheep subgroups had a significant $(\mathrm{p} \leq 0.001)$ live weight gain: P1, P3, P and D2. There are no significant $(\mathrm{p}>0.05)$ live weight differences for the following sheep subgroups: N1, D11, N2, D21, D22, N3, D31, D32, N and D1.

During the relevant research period, the live weight of the sheep of all subgroups (except D11 and N2) has increased. In the 2 nd research period, the sheep average live weight gain of subgroup N2 is negative $(-500 \mathrm{~g})$, but it is positive in the $3 \mathrm{rd}$ research period, which cannot be explained by the usage of concentrate feeding station. Such live weight changes could be

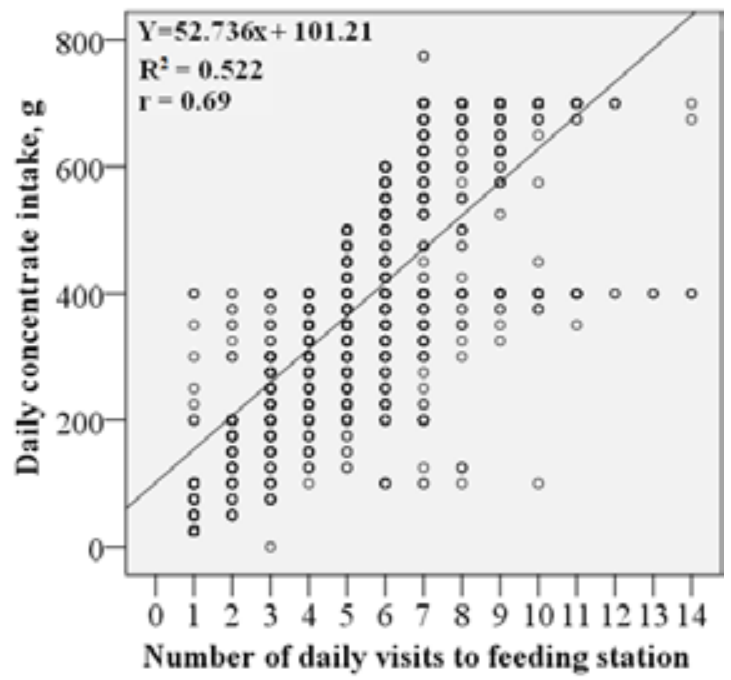

Figure 1. Relationship between daily number of visits to the feeding station and daily concentrate intake. 
Table 4

Sheep live weight changes during the research

\begin{tabular}{|c|c|c|c|c|}
\hline \multirow{3}{*}{ Group } & \multicolumn{2}{|c|}{ Live weight, $\mathrm{kg}$} & \multirow{3}{*}{$\begin{array}{l}\text { Live weight } \\
\text { difference, } \mathrm{kg}\end{array}$} & \multirow{3}{*}{ Significance } \\
\hline & before the research & after the research & & \\
\hline & \multicolumn{2}{|c|}{$\overline{\mathrm{x}} \pm \mathrm{S}_{\overline{\mathrm{x}}}$} & & \\
\hline 1st period total & $48.3 \pm 0.91$ & $51.2 \pm 0.86$ & 2.9 & $* * *$ \\
\hline N1 & $50.0 \pm 3.63$ & $51.2 \pm 3.81$ & 1.2 & n. $s$. \\
\hline P1 & $47.0 \pm 0.97$ & $50.6 \pm 0.96$ & 3.6 & $* * *$ \\
\hline D11 & $48.8 \pm 3.75$ & $48.5 \pm 2.50$ & -0.3 & n. s. \\
\hline D12 & $49.9 \pm 2.03$ & $52.5 \pm 1.76$ & 2.6 & $* *$ \\
\hline 2nd period total & $50.6 \pm 0.68$ & $51.0 \pm 0.62$ & 0.4 & n. s. \\
\hline $\mathrm{N} 2$ & $50.3 \pm 1.13$ & $49.8 \pm 1.07$ & -0.5 & n. s. \\
\hline $\mathrm{P} 2$ & $47.3 \pm 2.09$ & $49.9 \pm 1.49$ & 2.6 & $* *$ \\
\hline D21 & $51.4 \pm 1.28$ & $51.7 \pm 1.25$ & 0.3 & n. s. \\
\hline D22 & $51.8 \pm 1.36$ & $52.6 \pm 1.20$ & 0.8 & n. $s$. \\
\hline 3rd period total & $51.0 \pm 0.63$ & $52.3 \pm 0.69$ & 1.3 & $* * *$ \\
\hline $\mathrm{N} 3$ & $50.1 \pm 0.94$ & $50.6 \pm 0.94$ & 0.5 & n. s. \\
\hline $\mathrm{P} 3$ & $51.6 \pm 0.82$ & $53.7 \pm 0.82$ & 2.1 & $* * *$ \\
\hline D31 & $50.3 \pm 1.99$ & $51.6 \pm 1.99$ & 1.3 & n. s. \\
\hline D32 & $54.9 \pm 3.81$ & $56.9 \pm 3.81$ & 2.0 & n. s. \\
\hline
\end{tabular}

$* * \mathrm{p} \leq 0.01 ; * * * \mathrm{p} \leq 0.001 ; \mathrm{n}$. s. difference is not significant. N1, N2, N3 - group of sheep which did not visit the feeding station, P1, P2, P3 - group of sheep which visited the feeding station daily during all the period, D11, D21, D31 - subgroup of sheep which visited the automatic concentrate feeding station less than half of the number of days in the relevant period, D12, D22, D32 - subgroup of sheep which visited the feeding station more than half of the number of days in the relevant period.

related to the fact that before the 2 nd research period subgroup N2 sheep had received an unlimited amount of concentrate, but with distribution of concentrate by automatic feeding station, they no longer received the concentrate, which was followed by live weight loss. In the 3rd research period, the sheep of subgroup N3 did not receive any concentrate as well, yet an average live weight gain was observed.

Upon increasing the daily concentrate ration for each sheep from $400 \mathrm{~g}$ to $700 \mathrm{~g}$ in the $3 \mathrm{rd}$ research period, the group as a whole gets a significant live weight gain $(\mathrm{p}<0.001)$.

In the 3 rd research period, the sheep live weight gain in subgroups D31 and D32 is higher than the live weight gain of sheep from the relevant subgroups in the 2 nd research period (D21 and D22).

In different studies, it has been proved that during the grazing season diet supplementation with concentrate also significantly increases the feed intake of lambs (Bosing et al., 2014) and the feed intake of lactating ewes in postpartum period in comparison with the animals whose diets were not supplemented with concentrate (Joy et al., 2014).

In view of the sheep regrouping in the 2 nd and $3 \mathrm{rd}$ research periods and the time required for concentrate intake, when determining the daily concentrate ration in the amount of $400 \mathrm{~g}$ and $700 \mathrm{~g}$, the preferable size of a sheep group for one feeding station should not be more than 70 sheep.

\section{Conclusions}

1. During the research period, a part of sheep did not visit the automatic concentrate feeding station: in the 1 st period - $13 \%$ sheep, in the 2 nd and 3rd periods $-37 \%$ un $49 \%$, respectively.

2. Setting the daily ration for a sheep as $400 \mathrm{~g}$, the average daily number of visits to the concentrate feeding station was 6.1 (in the 1 st period) and 4.7 (in the 2nd period). Upon increasing the daily concentrate ratio up to $700 \mathrm{~g}$, the average daily number of visits to the feeding station was 6.9 (in the $3 \mathrm{rd}$ period). The number of visits to the concentrate feeding station varied $(\mathrm{V}>10 \%)$.

3. In the $1 \mathrm{st}, 2$ nd and 3rd periods live weight increased significantly $(\mathrm{p} \leq 0.05)$ for the subgroups of sheep which made regular visits to the feeding station. In the 1 st period there was a significant live weight gain $(p=0.006)$ for the subgroup of sheep, which visited the feeding station from 38 to 75 days. 
4. In all research periods, the quantity of average daily concentrate intake $(373.5 \mathrm{~g}$ in the 1 st period, $333.1 \mathrm{~g}$ in the $2 \mathrm{nd}$ period and $581.2 \mathrm{~g}$ in the 3rd period) was $93 \%, 83 \%$ and $83 \%$, respectively, of the maximum set ration $(400 \mathrm{~g}$ in the $1 \mathrm{st}$ and 2nd period, $700 \mathrm{~g}$ in the $3 \mathrm{rd}$ period).

\section{References}

1. Bath, D.L. (1982). Reducing fat in milk and dairy production by feeding. Journal of Dairy Science, 65 (3), 450 - 453. DOI: 10.3168/jds.S0022-0302(82)82213-3.

2. Bosing, B.M., Susenbeth, A., Hao, J., Ahnert, S., Ohm, M., \& Dickhoefer, U. (2014). Effect of concentrate supplementation on herbage intake and live weight gain of sheep grazing a semi-arid grassland steppe of North-Eastern Asia in response to different grazing management systems and intensities. Livestock Science, 165 (1), 157 - 166. DOI: 10.1016/j.livsci.2014.03.026.

3. Braun, U., Rihs, T., \& Schefer, U. (1992). Ruminal lactic acidosis in sheep and goats. Veterinary Record, 130, 343 - 349. DOI: 10.1136/vr.130.16.343.

4. Demment, M.W., \& Greenwood, G.B. (1987). The use of a portable computer for real-time recording of observations of grazing behaviour in the field. Journal of Range Management, 40 (3), $284-285$. Retrieved February 15, 2017, from: https://journals.uair.arizona.edu/index.php/jrm/article/view/8131/7743.

5. Enemark, J.M.D. (2008). The monitoring, prevention and treatment of sub-acute ruminal acidosis (SARA): a review. The Veterinary Journal, 176 (1), 32 - 43. DOI: 10.1016/j.tvj1.2007.12.021.

6. Hall, D.G., Holst, P.J., \& Shutt, D.A. (1992). The effect of nutritional supplements in late pregnancy on ewe colostrum production plasma progesterone and IGF-1 concentrations. Australian Journal of Agricultural Research, 43 (2), 325 - 337. DOI: 10.1071/AR9920325.

7. Hinch, G.N., Lynch, J.J., Nolan, J.V., Leng, R.A., Bindon, B.M., \& Piper, L.R. (1996). Supplementation of high fecundity Border Leicester $\times$ Merino ewes with a high protein feed: Its effect on lamb survival. Australian Journal of Experimental Agriculture, 36 (2), 129 - 136. DOI: 10.1071/EA9960129.

8. Jordan, D.J., \& Mayer, D.G. (1989). Effects of udder damage and nutritional plane on milk yield, lamb survival and lamb growth of Merinos. Australian Journal of Experimental Agriculture, 29 (3), 315 - 320. DOI: $10.1071 /$ EA9890315.

9. Joy, M., Ripoll-Boscha, R., Sanz, A., Molinoa, F., Blascoa, I., \& Alvarez-Rodraguez, J. (2014). Effects of concentrate supplementation on forage intake, metabolic profile and milk fatty acid composition of unselected ewes raising lambs. Animal Feed Science and Technology, 187, 19 - 29. DOI: 10.1016/j. anifeedsci.2013.09.014.

10. Kleeman, D.O., Walker, S.K., Walkley, J.R.W., Ponzoni, R.W., Smith, D.H., Grimson, R.J., \& Seamark, R.F. (1993). Effect of nutrition during pregnancy on birth weight and lamb survival in FecB Booroola $\times$ South Australian Merino ewes. Animal Reproduction Science, 31 (3 - 4), 213 - 224. DOI: 10.1016/03784320(93)90006-D.

11. Krause, K.M., \& Oetzel, G.R. (2006). Understanding and preventing subacute ruminal acidosis in dairy herds: a review. Animal Feed Science and Technology, 126 (3 - 4), 215 - 236. DOI: 10.1016/j. anifeedsci.2005.08.004.

12. Mellor, D.J., Flint, D.J., Vernon, R.G., \& Forsyth, I.A. (1987). Relationships between plasma hormone concentrations, udder development and the production of early mammary secretions in twin-bearing ewes on different planes of nutrition. Quarterly Journal of Experimental Physiology and Cognate Medical Sciences, 72 (3), 345 - 356. DOI: 10.1113/expphysiol.1987.sp003080.

13. Ocak, N., Cam, M.A., \& Kuran, M. (2005). The effect of high dietary protein levels during late gestation on colostrum yield and lamb survival rate in singleton-bearing ewes. Small Ruminant Research, 56 (1 - 3), 89 - 94. DOI: 10.1016/j.smallrumres.2004.02.014.

14. O’Doherty, J.V., \& Crosby, T.F. (1996). The effect of diet in late pregnancy on progesterone concentration and colostrum yield in ewes. Theriogenology, 46 (2), 233 - 241. DOI: 10.1016/0093-691X(96)00180-X.

15. Plaizier, J.C., Krause, D.O., Gozho, G.N., \& McBride, B.W. (2009). Subacute ruminal acidosis in dairy cows: the physiological causes, incidence and consequences. The Veterinary Journal, 176 (1), $21-31$. DOI: $10.1016 /$ j.tvj1.2007.12.016.

16. Robinson, J.J., McEvoy, T.G., \& Sinclair, K.D. (1999). Nutritional effects on foetal growth. Animal Science, 68 (2), 315 - 331. DOI: 10.1017/S1357729800050323.

17. Stone, W.C. (2004). Nutritional approaches to minimize subacute ruminal acidosis and laminitis in dairy cattle. Journal of Dairy Science, 87 (SUPPL. 1), E13 - E26. DOI: 10.3168/jds.S0022-0302(04)70057-0.

18. Ungar, E.D. (1996). Ingestive behaviour. In J. Hodgson \& A.W. Illius (Eds.), The Ecology and Management of Grazing Systems (pp. 185 - 218). Wallingford, UK: CAB International. 
19. Unwin, D.M., \& Martin, P. (1987). Recording behaviour using a portable microcomputer. Behaviour, 101 (1), 87 - 100. DOI: 10.1163/156853987X00387.

20. Wendl, G., Wendling, F., Wagner, M., \& Pirkelmann, H. (1999). A feed station for automatic recording of sheep intake. Landtechnik, 54 (5), $304-305$. 